\title{
Suscetibilidade a enchentes: estudo de caso na microbacia hidrográfica do Córrego da Onça em Três Lagoas - MS
}

Susceptibility to floods: a case study in the watershed of Córrego da Onça in Três Lagoas - MS

Susceptibilidad a las inundaciones: estudio de caso en la microcuenca del Córrego da Onça en Três Lagoas - MS

João Miguel Merces Bega Mestrando em Recursos Hídricos e Tecnologias Ambientais, FEIS-UNESP. joaomiguelbega@gmail.com

Natasha Ulhiana Ferreira Ribeiro Mestranda em Recursos Hídricos e Tecnologias Ambientais, FEIS-UNESP. natasha_ul@yahoo.com.br

César Gustavo da Rocha Lima Professor Doutor, FEIS-UNESP. cesarlima@dec.feis.unesp.br 


\section{RESUMO}

O processo de urbanização, que vem crescendo exponencialmente desde a segunda metade do século 20 , afeta diretamente a dinâmica hidrológica nas bacias de drenagem devido às alterações que engendram no uso e ocupação do solo. Como consequência, em relação ao volume de água precipitado, há o aumento da parcela escoada superficialmente e a redução da infiltração, o que contribui para a ocorrência de enchentes. O objetivo do presente trabalho foi avaliar a suscetibilidade a enchentes na microbacia hidrográfica do Córrego da Onça, localizada na área urbana de Três Lagoas - MS. Foram utilizados índices morfométricos e levantamento de dados dos cursos d'água e do uso e ocupação do solo da microbacia. Para a análise do uso e ocupação do solo, realizou-se uma classificação supervisionada, utilizando-se de imagens do Landsat-5 sensor TM (Thematic Mapper) para os anos de 1990, 2000 e 2010 e do Landsat-8 sensor OLI (Operational Land Imager) para o ano de 2018, sendo tratadas no software SPRING 5.4.3. Os resultados indicaram que os índices morfométricos possibilitaram um melhor entendimento da dinâmica hídrica natural que forma a microbacia, porém não foram suficientes para inferir a suscetibilidade da mesma a enchentes. Todavia, utilizando-se dos perfis longitudinal e transversais do canal, em conjunto com os dados sobre o uso e ocupação do solo, concluiu-se que, devido ao seu relevo plano e à intensa urbanização, a microbacia do Córrego da Onça tem tendência favorável a enchentes.

PALAVRAS-CHAVE: Urbanização. Georreferenciamento. Impermeabilização.

\section{ABSTRACT}

The urbanization process, which has been growing exponentially since the second half of the 20th century, directly affects the hydrological dynamics in the drainage basins due to the changes that engender the use and occupation of the soil. As a consequence, in relation to the volume of precipitated water, there is the increase of the surfacedrained portion and the reduction of infiltration, which contributes to the occurrence of floods. The objective of this work was to evaluate the susceptibility to floods in the watershed of Córrego da Onça, located in the urban area of Três Lagoas - MS. Morphometric indexes and data collection of watercourses and soil use and occupation of the basin were used. For the analysis of land use and occupation, a supervised classification was carried out, using images from the Landsat-5 sensor TM (Thematic Mapper) for the years 1990, 2000 and 2010 and the Landsat-8 OLI sensor (Operational Land Imager) for the year 2018, being treated in the software SPRING 5.4.3. The results indicated that the morphometric indexes allowed a better understanding of the natural hydrological dynamics that form the watershed, but were not enough to infer the susceptibility of the same to floods. However, using the longitudinal and transverse profiles of the channel, together with data on land use and occupation, it was concluded that due to its flat relief and intense urbanization, the Córrego da Onça watershed has a favorable trend to floods.

KEYWORDS: Urbanization. Georeferencing. Impermeabilization.

\section{RESUMEN}

El proceso de urbanización, que viene creciendo exponencialmente desde la segunda mitad del siglo 20, afecta directamente la dinámica hidrológica en las cuencas de drenaje debido a las alteraciones que engendran en el uso y ocupación del suelo. Como consecuencia, en relación al volumen de agua precipitado, hay el aumento de la porción escurrida superficialmente y la reducción de la infiltración, lo que contribuye a la ocurrencia de inundaciones. El objetivo del presente trabajo fue evaluar la susceptibilidad a las inundaciones en la microcuenca hidrográfica del Córrego da Onça, ubicada en el área urbana de Três Lagoas - MS. Se utilizaron índices morfométricos y levantamiento de datos de los cursos de agua y del uso y ocupación del suelo de la microcuenca. Para el análisis del uso y ocupación del suelo, se realizó una clasificación supervisada, utilizando imágenes del Landsat-5 sensor TM (Thematic Mapper) para los años 1990, 2000 y 2010 y del Landsat-8 sensor OLI (Operational) Land Imager) para el año 2018, siendo tratadas en el software SPRING 5.4.3. Los resultados indicaron que los índices morfométricos posibilitar un mejor entendimiento de la dinámica hídrica natural que forma la microbacia, pero no fueron suficientes para inferir la susceptibilidad de la misma a las inundaciones. Sin embargo, utilizando los perfiles longitudinal y transversales del canal, junto con los datos sobre el uso y ocupación del suelo, se concluyó que, debido a su relieve plan ya la intensa urbanización, la microcuenca del Córrego da Onça tiene tendencia favorable a las inundaciones.

PALABRAS CLAVE: Urbanización. Georreferenciación. Impermeabilización. 


\section{INTRODUÇÃO}

A população urbana mundial, a partir da segunda metade do século 20 , tem passado por um crescimento exponencial de forma descontrolada e caótica (UNITED NATIONS, 2014). Desde então, as atividades antrópicas no meio vêm se consolidando em um ritmo cada vez maior, o que gera impactos negativos nos ecossistemas naturais (SOARES et al., 2017). Como consequência, verifica-se uma mudança no uso e ocupação do solo, ocasionando um aumento da vazão instantânea dos cursos d'água por meio da impermeabilização da superfície, o que altera a magnitude, o caminho e a velocidade do escoamento superficial e resulta em problemas de enchentes (WALSH et al., 2005; FOX et al., 2012; DAMS et al., 2013; GUO, 2013). Diversos fatores estão diretamente ligados ao processo de modificação da cobertura do solo, que pode influenciar na disponibilidade e na qualidade dos recursos naturais, além de afetar a biodiversidade em grandes áreas do planeta (MENDONZA et al., 2011). No que tange às alterações no ciclo hidrológico, por exemplo, a urbanização provoca uma diminuição da infiltração da água precipitada, com redução da recarga dos aquíferos, causando, consequentemente, um aumento no escoamento superficial direto (TUCCl, 2004).

Faz-se necessário, então, que o desenvolvimento e a gestão ambiental de uma cidade se baseiem em princípios básicos de planejamento, como quantificar os impactos da urbanização sobre o escoamento, analisar as características e parâmetros físicos da área, estudar o comportamento e controle dos efluentes e considerar a bacia como um todo, já que todos os fatores que afetam a produção e o equilíbrio do meio ambiente refletem sobre suas características físicas, bióticas e antrópicas (SILVA, 2016).

O município de Três Lagoas (MS), inserido na microbacia hidrográfica do Córrego da Onça, tem sido alvo de um crescimento acelerado e dinâmico devido à implantação de novas indústrias e loteamentos que ocorrem anualmente (BRASIL, 2017). Além do mais, a declividade plana da região e a falta de planejamento adequado à sua expansão, corroboram para a existência de possíveis problemas relacionados à drenagem pluvial e à degradação ambiental dos ecossistemas aquáticos (Américo et al., 2015).

Diante do quadro apresentado, este trabalho objetivou avaliar a suscetibilidade a enchentes da microbacia hidrográfica do Córrego da Onça por meio da análise de índices morfométricos e, posteriormente, levantar dados sobre as modificações antrópicas no uso e ocupação do solo para que questões relevantes ao estudo sejam esclarecidas.

\section{MATERIAIS E MÉTODOS}

A microbacia hidrográfica do Córrego da Onça (Figura 1) localiza-se em uma cidade de médio porte da Mesorregião Leste do Estado do Mato Grosso do Sul, Três Lagoas, situada entre as coordenadas geográficas: $51^{\circ} 30^{\prime} 12^{\prime \prime}$ W e $52^{\circ} 30^{\prime} 00^{\prime \prime}$ W; $19^{\circ} 30^{\prime} 00^{\prime \prime} \mathrm{S}$ e $21^{\circ} 05^{\prime} 27^{\prime \prime} \mathrm{S}$. De grande relevância para a região, a microbacia tem sofrido um intenso processo de degradação decorrente de interferências da urbanização (AMÉRICO, 2010). 
Figura 1: Área de estudo

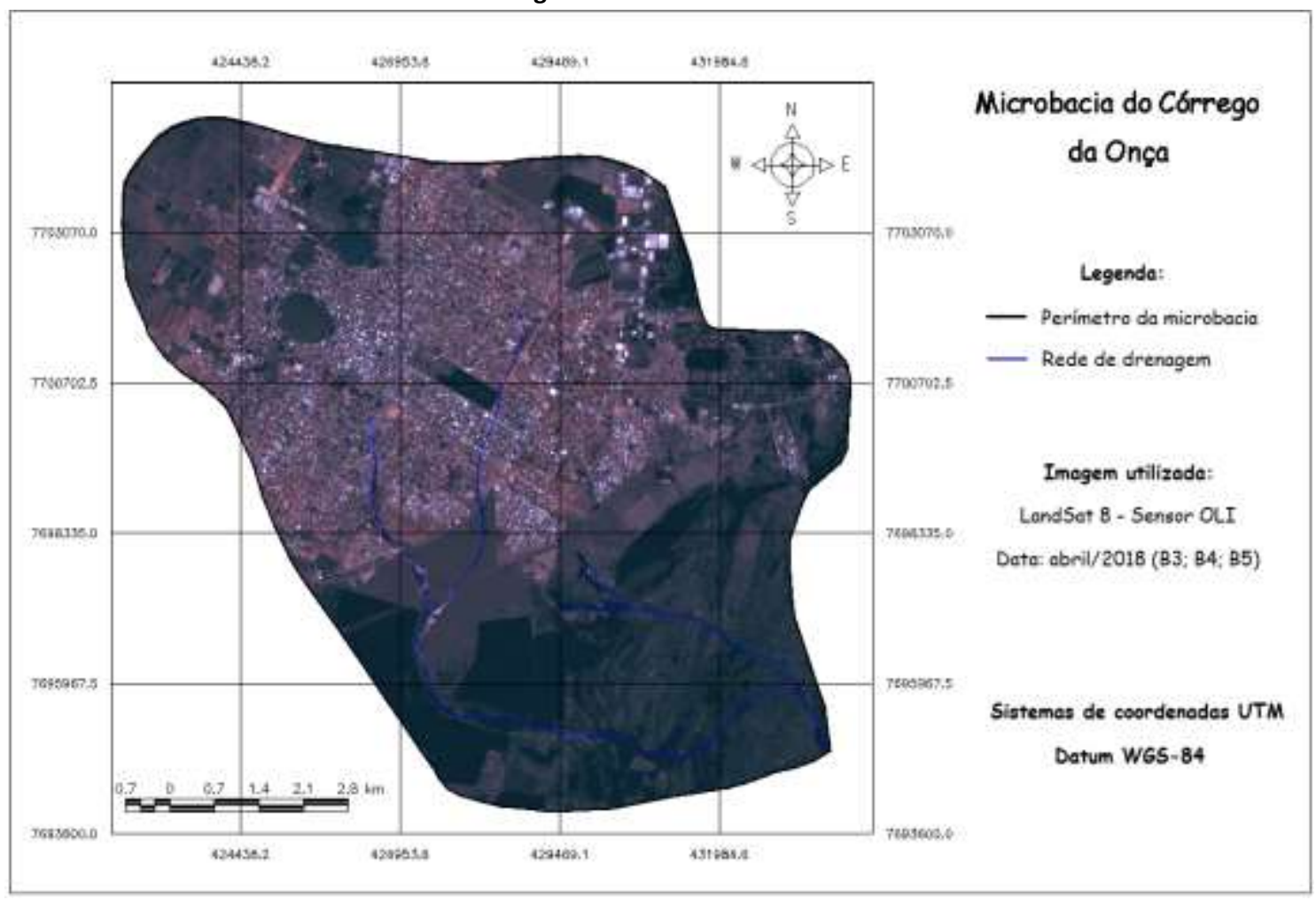

Fonte: Elaborado pelos autores.

Segundo a classificação de Köppen, a área de estudo possui tipo climático Aw, com estações chuvosa e seca bem definidas, ocorrendo, respectivamente, no verão e no inverno (ALVARES et al., 2013). Além disso, caracteriza-se por ser bem segmentada quanto ao uso e ocupação do solo, ter condições de superfície com vegetação tradicional do Cerrado pouco preservada e solo arenoso e sensível (CARVALHO, 2010).

Para que se verificasse a suscetibilidade da microbacia a enchentes, foram realizados os cálculos de três índices morfométricos. O primeiro, denominado coeficiente de compacidade $\left(\mathrm{K}_{\mathrm{c}}\right)$ (Equação 1), relaciona o perímetro da bacia $\left(\mathrm{P}_{\mathrm{BH}}\right)$ com a circunferência de uma área circular igual à área da bacia $\left(\mathrm{P}_{\mathrm{C}}\right)$.

$$
\mathrm{K}_{\mathrm{c}}=\frac{\mathrm{P}_{\mathrm{BH}}}{\mathrm{P}_{\mathrm{C}}}=0,28 * \frac{\mathrm{P}_{\mathrm{BH}}}{\sqrt{\mathrm{A}}}
$$

O seu valor, sempre maior ou igual a 1, indica que a bacia de drenagem possui alta propensão a enchentes quando situado entre 1,00 e 1,25; tendência mediana a enchentes quando se encontra entre 1,25 e 1,50; e não sujeita a enchentes quando maior que 1,50 (Lima et al., 2013).

$\mathrm{O}$ segundo índice, denominado fator de forma $\left(\mathrm{K}_{\mathrm{f}}\right)$, estabelece a razão entre a largura média $\left(\mathrm{L}_{\mathrm{m}}\right)$ e o comprimento do eixo (L) da bacia (Equação 2). 


$$
\mathrm{K}_{\mathrm{f}}=\frac{\mathrm{L}_{\mathrm{m}}}{\mathrm{L}}=\frac{\mathrm{A}}{\mathrm{L}^{2}}
$$

Os resultados de $\mathrm{K}_{\mathrm{f}}$ com valores entre 0,75 e 1,00 indicam que a bacia é sujeita a enchentes; enquanto valores entre 0,75 e 0,50 e valores menores do que 0,50 indicam que a bacia, respectivamente, tem tendência mediana a enchentes e que não é sujeita à mesma (Lima et al., 2013).

O terceiro e último parâmetro, a densidade de drenagem (D), é apresentado na Equação 3, que o descreve como a razão entre o comprimento total dos cursos d'água $\left(\mathrm{L}_{t}\right)$ e a área da bacia (A).

$$
\mathrm{D}=\frac{\mathrm{L}_{\mathrm{t}}}{\mathrm{A}}
$$

Segundo Villela e Matos (1975), densidades de drenagem que obtiverem valores maiores do que 3,5 indicam bacias excepcionalmente bem drenadas, enquanto valores próximos a 0,5 indicam bacias com drenagens pobres.

A análise da mudança no uso e ocupação do solo, por sua vez, foi realizada utilizando imagens de satélite do Landsat-5 sensor TM (Thematic Mapper), para os anos de 1990 (Data: 25/maio), 2000 (Data: 02/abril) e 2010 (Data: 14/abril) (B2-B; B3-R; B4-G) e do Landsat-8 sensor OLI (Operational Land Imager), para o ano de 2018 (Data: 29/abril) (B3-B; B4-R; B5-G). Em seguida, foi feita a classificação supervisionada por pixel pelo método MaxVer utilizando o software SPRING 5.4.3. As classes quantificadas foram: corpos d'água, solo exposto, urbano, vegetação arbórea (árvores de grande porte), vegetação rasteira (gramíneas e arbustos) e vegetação rala (intermediário entre solo exposto e vegetação rasteira). Como resultado, obteve-se um desempenho médio acima de $93 \%$ para as quatro imagens analisadas, que passaram por uma pós-classificação manual para ajustar pequenas inconsistências visuais. Por último, com os mapas gerados, extraiu-se os dados das áreas ocupadas pelas diferentes classes.

\section{RESULTADOS E DISCUSSÃO}

À priori, levantaram-se alguns dados do canal principal, com o intuito de verificar o relevo plano do município, sendo obtidos seu perfil longitudinal (Figura 2) e os perfis transversais na cabeceira, no médio curso e no baixo curso do mesmo (Figura 3). Verificou-se no perfil longitudinal que a sua declividade é baixa na maioria do seu curso, caracterizado por ser relativamente plano. No que tange aos perfis transversais, observou-se que o canal nos três locais analisados tem baixa profundidade, além do seu leito de inundação ser plano. Essas características contribuem para que a microbacia tenha tendência a enchentes.

Os valores da área da bacia $\left(84,37 \mathrm{~km}^{2}\right)$; perímetro da bacia $(37,70 \mathrm{~km})$; perímetro de circunferência de mesma área $(32,56 \mathrm{~km})$; e canal principal $(12,40 \mathrm{~km})$, necessários para o cálculo dos índices morfométricos, foram encontrados utilizando ferramentas do SPRING. 
Como resultado da urbanização não planejada, o comprimento total dos canais variou, passando de 27,16 km em 1990 para 23,37 km em 2018.

Figura 2: Perfil longitudinal do canal principal

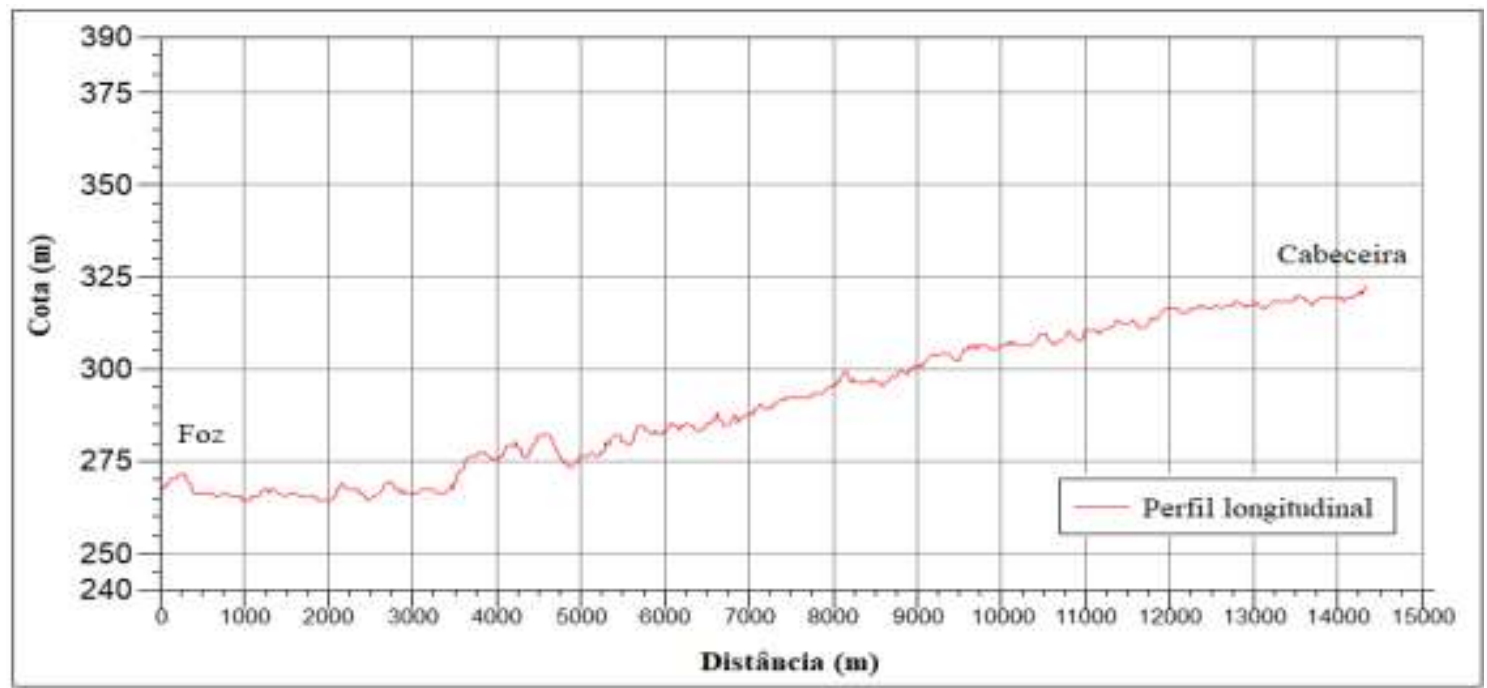

Fonte: Elaborado pelos autores.

Figura 3: Perfis transversais ao longo do canal principal

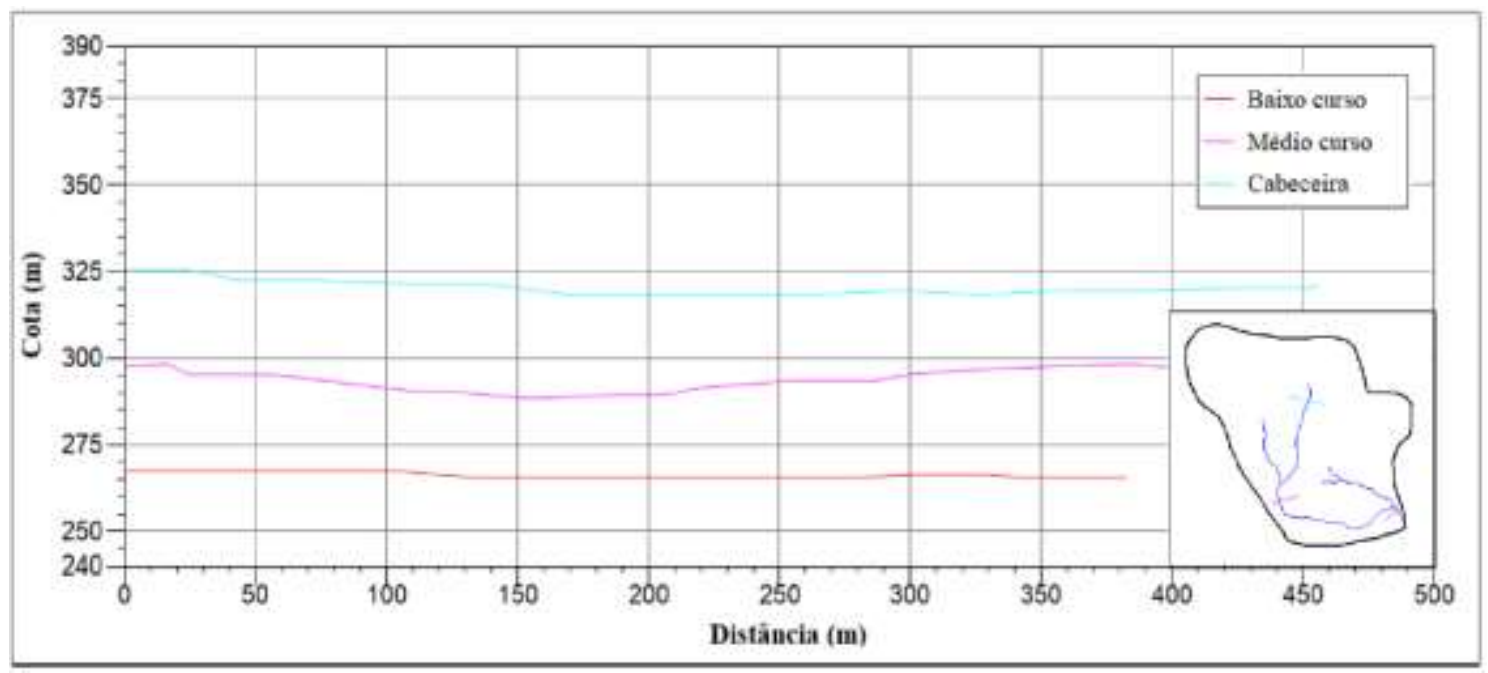

Fonte: Elaborado pelos autores.

Na sequência, calcularam-se o coeficiente de compacidade $\left(K_{c}\right)$, o fator de forma $\left(K_{f}\right)$ e a densidade de drenagem (D), apresentados na Tabela 1: 
Tabela 1: Coeficientes para aferição de suscetibilidade a enchentes

\begin{tabular}{c|c} 
Coeficiente & Valor encontrado \\
\hline $\mathrm{K}_{\mathrm{c}}$ & 1,16 \\
\hline $\mathrm{K}_{\mathrm{f}}$ & 0,55 \\
\hline $\mathrm{D}_{1990}$ & $0,32 \mathrm{~km}^{-1}$ \\
\hline $\mathrm{D}_{2018}$ & $0,28 \mathrm{~km}^{-1}$
\end{tabular}

$\mathrm{D}_{1990}$ : densidade de drenagem em 1990; $\mathrm{D}_{2018}$ : densidade de drenagem em 2018. Fonte: Elaborado pelos autores.

De acordo com a classificação apresentada por Lima et al. (2013), pode-se observar que o $\mathrm{K}_{\mathrm{f}}$ apresentou valor entre 0,50 e 0,75, incluindo-o na categoria de área com tendência mediana a enchentes, o que confere à microbacia do Córrego da Onça um formato medianamente alongado, largo e próximo a de um retângulo (Santos et al., 2018). Villela e Mattos (1975) verificaram que quanto mais próximo de zero forem os valores dos coeficientes morfométricos, mais a bacia é alongada, formato que resulta em uma distribuição homogênea da chegada do escoamento superficial no curso d'água receptor, reduzindo as chances de enchentes quando comparada à uma bacia circular, com uma concentração do deflúvio superficial gerado na bacia em um único ponto, seu centro.

O coeficiente de compacidade de 1,16 encontrado, por sua vez, inclui a microbacia do Córrego da Onça na classificação de alta propensão a grandes enchentes (Lima et al., 2013), aproximando sua forma à de um círculo, o que eleva a probabilidade de ocorrência do fenômeno analisado.

Para o último parâmetro calculado, a densidade de drenagem, encontraram-se dois diferentes valores, 0,32 $\mathrm{km}^{-1}$ para 1990 e $0,28 \mathrm{~km}^{-1}$ para 2018, ambos indicando, portanto, uma drenagem pobre (Villela e Mattos, 1975). O tipo de drenagem encontrado indica a existência de um maior tempo de percurso da água no solo em relação ao curso d'água, o que favorece uma distribuição homogênea do escoamento superficial que atinge os corpos hídricos, visto que a velocidade da água no solo é menor que no canal. Além disso, a drenagem pobre proporciona uma diminuição da vazão de pico e um aumento do tempo de base em um hidrograma de cheia, quando comparado à uma bacia excepcionalmente bem drenada.

Por conseguinte, a área de estudo demonstrou não ser suscetível a enchentes quanto à densidade de drenagem. Granell-Pérez (2011) afirma que uma baixa densidade de drenagem, dentro outros fatores, indica um relevo suave e relativamente plano. Para Santos et al. (2018), a densidade de drenagem figura apenas um indicador das características físicas e naturais da bacia hidrográfica analisada, estando a veracidade de seu resultado comprometida, já que este parâmetro não considera a área impermeabilizada sobre o ciclo hidrológico. Além do mais, a densidade de drenagem não representa as mudanças antrópicas no meio, visto que pela mudança no uso e ocupação do solo, a velocidade na superfície sofre alteração.

Como os resultados das variáveis morfométricas diferiram entre si, verificando-se um parâmetro sujeito $\left(\mathrm{K}_{\mathrm{c}}\right)$, um parcialmente sujeito $\left(\mathrm{K}_{\mathrm{f}}\right)$ e outro não sujeito $(\mathrm{D})$, não foi possível inferir sobre a suscetibilidade da microbacia a enchentes.

Assim, para esclarecer o comportamento da microbacia quanto ao fenômeno analisado, fez-se necessário avaliar outros aspectos naturais e antropogênicos da área que fossem além dos 
parâmetros calculados. Relatórios municipais, por exemplo, mostram problemas frequentes com enchentes no Córrego da Onça, fato que corrobora com os resultados obtidos nas análises dos perfis longitudinal e transversais aqui expostos (Figuras 2 e 3 ).

No intuito de obter informações sobre as mudanças no uso e ocupação do solo nas três últimas décadas, apresenta-se a Figura 4. A Figura 5 mostra os valores, em área, correspondentes a cada uma das classes analisadas, nos respectivos anos estudados.

Figura 4: Mudanças no uso e ocupação do solo na microbacia do Córrego da Onça entre os anos de 1990 e 2018

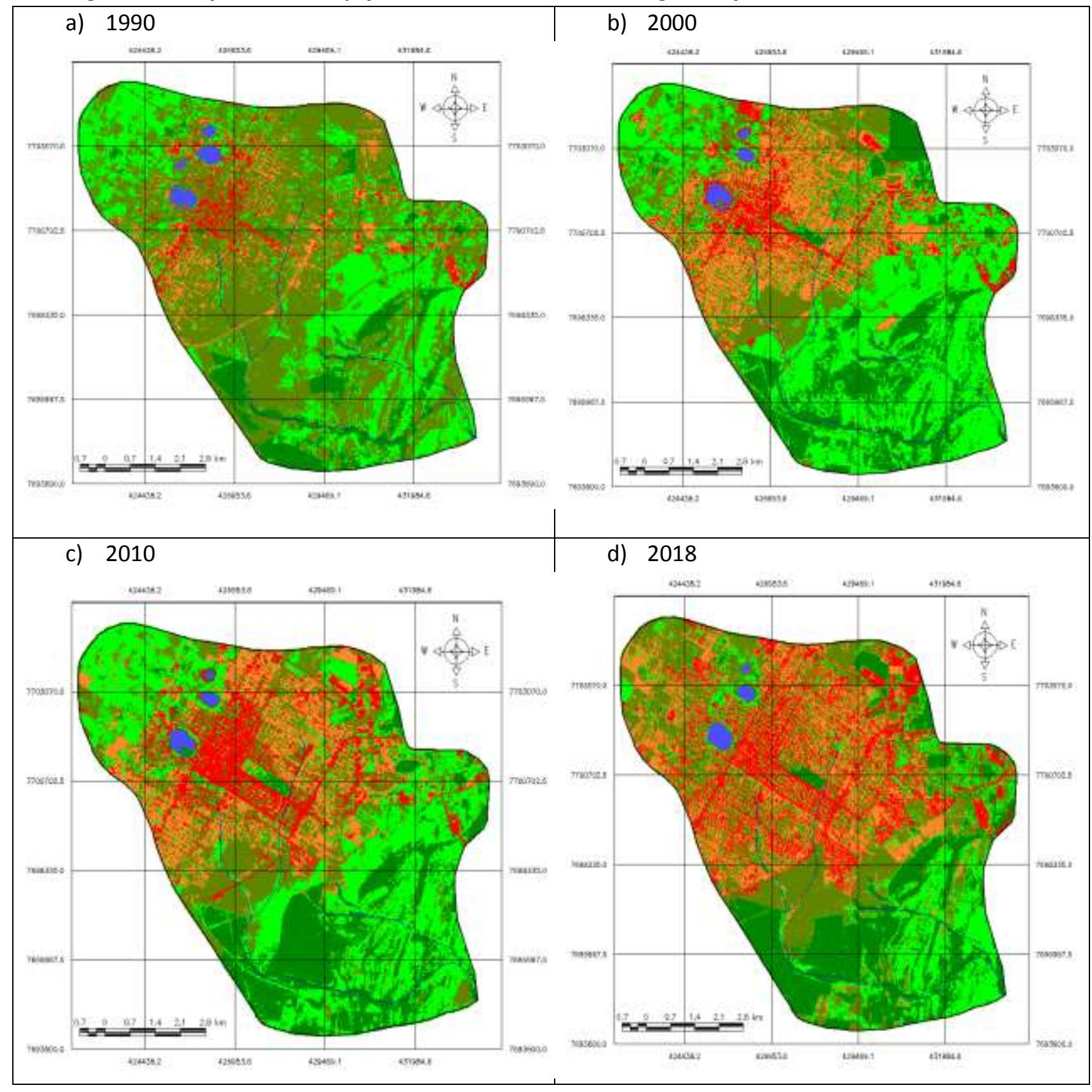


Legenda:

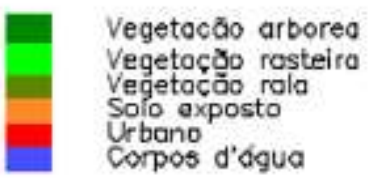

Vegetocð̃o arboreo

Vegetoçס̄o rosteira

Compos d'ógue
Sistemas de coordenadas UTM

Datum WGS-84

Fonte: Elaborado pelos autores.

Figura 5: Variação da distribuição do uso e ocupação do solo

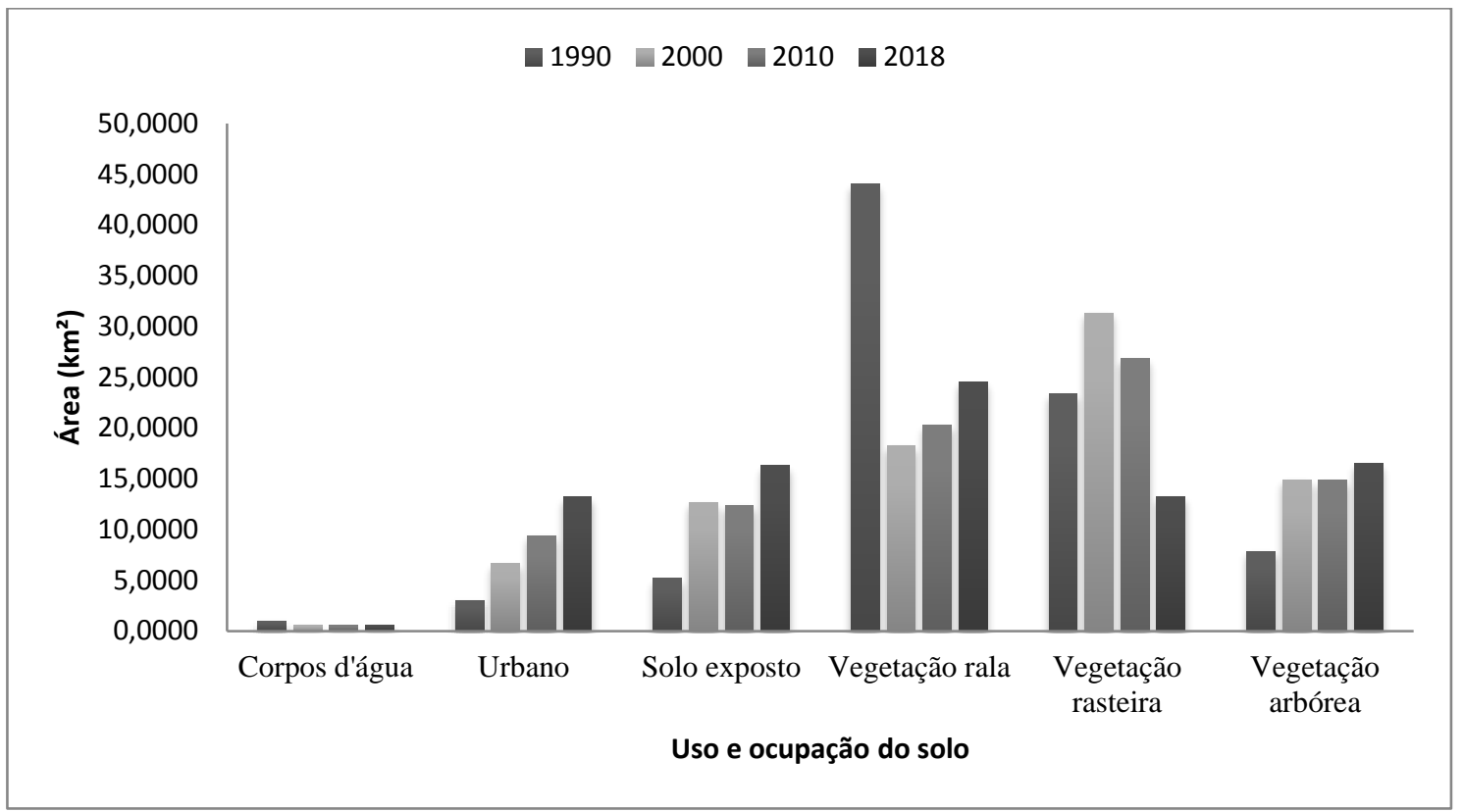

Fonte: Elaborado pelos autores.

Observa-se que a malha urbana sofreu um crescimento gradual, bem como um aumento significativo da vegetação arbórea entre os anos de 1990 e 2000, devido à crescente preocupação ambiental, com aplicação de políticas de Áreas de Proteção Ambiental (APPs), o que apresenta inúmeros benefícios ao meio (Rech et al., 2015). Em seu plano diretor, Três Lagoas conta com um Sistema de Áreas Verdes, constituído por um conjunto de áreas protegidas pela legislação, indicando uma tentativa de difusão de práticas sustentáveis.

A expansão e desenvolvimento das cidades brasileiras, em sua totalidade, foi marcado por uma degradação dos recursos naturais. Tam e Nga (2018), em um estudo realizado em Hanoi, Vietnã, verificaram um decréscimo no nível das águas subterrâneas em consequência da explotação em excesso e, em menor intensidade, das mudanças na cobertura vegetal. A respeito dos recursos superficiais, Zambrano et al. (2017) inferiram que a má qualidade da água encontrada em um córrego urbano de llha Solteira (SP) se relaciona à cobertura do solo e à possível existência de ligações clandestinas. Cenário similar é encontrado no Córrego da Onça, inserido na microbacia hidrográfica de interesse. Souza et al. (2018) apresentaram como responsáveis pelo estado atual de deterioração deste curso d'água, na parte a céu aberto, as 
ligações clandestinas de esgoto doméstico, o assoreamento de parte do canal e, por fim, o lançamento de águas pluviais.

Constatou-se que entre os anos de 1990 e 2000 houve um aumento da classe urbana em aproximadamente $120 \%$, valor que não se manteve constante nas décadas posteriores, com um crescimento médio de $41 \%$ entre elas. A elevada expansão da malha urbana verificada entre 1990 e 2000 ocorreu, principalmente, do sentido noroeste para a região central da cidade e foi, em sua maioria, decorrente da instalação de indústrias na região. Além disso, verificou-se um aumento na pavimentação das ruas e avenidas principais.

Em relação aos corpos d'água, caracterizados em suma pelas três lagoas, eles tiveram pouca alteração desde 1990. Neste ano, o valor encontrado foi, em média, $25 \%$ maior que os encontrados em 2000, 2010 e 2018. De acordo com Souza et al. (2018), a canalização do Córrego da Onça, realizada em perímetro urbano, foi feita de maneira descontrolada, resultando em um agravamento da degradação ambiental da região. No percurso a céu aberto, os autores verificaram degradação da mata ciliar que entorna o Córrego da Onça. Américo et al. (2015) realizaram um monitoramento em pontos de amostragem ao longo do córrego e nas lagoas entre out./2008 e set./2009, onde verificaram que onze de doze amostras coletadas não atenderam a Resolução CONAMA n³57/05 quanto à concentração de oxigênio dissolvido, o que se justificou pela vazão nula no curso d'água, principalmente em época de estiagem, impossibilitando a diluição do efluente lançado pela ETE.

Quanto ao solo exposto, um aumento de aproximadamente $90 \%$ foi verificado entre os anos de 1990 e 2000, e $11 \%$ de 2010 para 2018. O resultado encontrado deve-se, em menor intensidade, às práticas agrícolas da região e, em sua maioria, por se tratar de uma microbacia altamente urbanizada, à implantação de novos loteamentos, que demandam a divisão dos lotes por meio de ruas não pavimentas, como pode ser observado na região periférica da cidade (Figura 4).

De acordo com Bhagowat e Ahamad (2019) e Wang et al. (2019), a agricultura é a principal responsável pelo aporte de nutrientes nas matrizes aquáticas, podendo levar à eutrofização de ecossistemas aquáticos lênticos. Entre os anos de 1990 e 2000, observou-se um aumento em área da vegetação rasteira, o que sugere uma maior atividade agrícola neste período em relação aos outros analisados, e uma queda de aproximadamente 50\% entre 2010 e 2018, indicando uma possível redução do aporte de nutrientes provenientes desta fonte. Entretanto, na microbacia analisada, a malha urbana expandiu no decorrer dos anos, sendo a poluição urbana a principal provedora de nutrientes aos corpos hídricos locais, tendo as ligações clandestinas como fator preponderante, conforme verificado por Souza et al. (2018) e demonstrado na qualidade das águas por Américo et al. (2015).

Para a classe urbana, tem-se que entre os anos de 1990 e 2018, no que diz respeito à densidade de drenagem, o tempo de percurso da água precipitada no solo sofreu alteração, visto que a velocidade do fluido em superfícies impermeabilizadas é maior do que em superfícies vegetadas. Assim, apesar de o parâmetro da densidade de drenagem (D) ter indicado que a microbacia não é sujeita a enchentes, entende-se que a sua aplicação em áreas urbanas não expressa efetivamente o que realmente ocorre. 
Evidencia-se a ocorrência do fenômeno de enchentes quando há eventos de precipitação intensa no município de Três Lagoas. O risco está diretamente ligado aos processos desencadeados pelas mudanças no uso e ocupação do solo, que levam, num período de maior pluviosidade, ao extravasamento das águas fluviais para além do canal. Desta forma, os fatores condicionantes ao fenômeno no município estudado estão ligados às atividades antrópicas de modificação do meio, como a impermeabilização do solo, canalização de parte do curso d'água, ocupação desordenada das residências e indústrias e retirada de vegetação ao longo das margens fluviais.

\section{CONCLUSÕES}

Não foi possível concluir sobre a suscetibilidade a enchentes da microbacia hidrográfica do Córrego da Onça utilizando apenas os índices morfométricos. Estes, porém, forneceram informações relevantes das características físico-naturais da área, que auxiliaram no entendimento do comportamento da dinâmica natural que a forma. Como o conhecimento das ações antrópicas sobre o meio auxiliam no estudo sobre enchentes, estas foram avaliadas para permitir uma melhor análise.

Desta forma, concluiu-se que a microbacia do Córrego da Onça é, atualmente, suscetível a enchentes devido à sua baixa declividade, à acelerada urbanização da área e, em menor parcela, à sua forma.

\section{REFERÊNCIAS BIBLIOGRÁFICAS}

AMÉRICO, J. H. P. Ocorrência de Compostos Farmacológicos no Córrego da Onça, Município de Três Lagoas - MS. Dissertação (Mestrado) - Faculdade de Engenharia Civil na área de recursos hídricos e tecnologias ambientais, Universidade Estadual Paulista - UNESP, Ilha Solteira, 2010, 101 p.

AMÉRICO, J. H. P.; MANOEL, L. O.; TORRES, N. H. Avaliação de parâmetros físico-químicos da água do Córrego da Onça, Três Lagoas - MS. Fórum Ambiental da Alta Paulista, v. 11, n. 6, 2015, p. 250-257.

ALVARES, C. A.; STAPE, J. L.; SENTELHAS, P. C.; GONÇALVES, J. L. M.; SPAROVEK, G. Köppen's climate classification map for Brazil. Meteorologische Zeitschrift, v. 22, n. 6, 2013, p. 711-728.

BHAGOWATI, B.; AHAMAD, K. U. A review on lake eutrophication dynamics and recent developments in lake modeling. Ecohydrology \& Hydrobiology, v. 19, 2019, p. 155-166.

BRASIL. PlanMob Três Lagoas. Plano Diretor de Mobilidade Urbana. Três Lagoas, 2017.

CARVALHO, A. G. B. M. Proposição de geoindicadores para caracterização da degradação do meio físico na bacia hidrográfica do Córrego Onça, Três Lagoas - MS. Dissertação (Mestrado) - Faculdade de Engenharia Civil na área de recursos hídricos e tecnologias ambientais, Universidade Estadual Paulista - UNESP, Ilha Solteira, 2010. 132 p.

DAMS, J.; BATELAAN, O.; DUJARDIN, J.; REGGERS, J. Mapping impervious surface change from remote sensing for hydrological modeling. Journal of Hydrology, v. 485, 2013, p. 84-95.

FOX, D. M.; WITZ, E.; BLANC, V.; SOULIÉ, C.; NAVARRO, N. P.; DERVIEUX, A. 2012. A case study of land cover change (1950-2003) and runoff in a Mediterranean catchment. Applied Geography, v. 32, n. 2, 2012, p. 810-821.

GRANELL-PÉREZ, M. C. (2001). Trabalhando Geografia com as cartas topográficas. $1^{\circ}$ Edição, EditoriaUnijuí, ljuí. 
GUO, J. C. Y. Green concept in storm water management. Irrigation \& Drainage Systems Engineering, v. 2, n. 3, 2013, p. 1-8.

LIMA, G. C.; SILVA, M. L. N.; CURI, N.; SILVA, M. A.; OLIVEIRA, A. H.; AVANZI, J. C.; FREITAS, D. A. F. Estimativa do potencial de recarga na Sub-bacia das Posses, Extrema (MG), em função dos atributos fisiográficos, pedológicos e topográficos. Geociências, v. 32, n. 1, 2013, p. 51-62.

MENDONZA, M. E.; GRANADOS, E. L.; GENELETTI, D.; PÉREZ-SALICRUP, D. R.; SALINAS, V. Analysis in gland cover and land use change process at watershed level: A multi temporal study in the Lake Cuitzeo Watershed, Mexico (1975-2003). Applied Geography, v.31, 2011, p.237-350.

RECH, C. C. C.; SILVA, A. C.; HIGUCHI, P.; SCHIMALSKI, M. B.; PSCHEIDT, F.; SCHMIDT, A. B.; ANSOLIN, R. D.; BENTO, M. A.; MISSIO, F. F.; LOEBENS. Avaliação da restauração florestal de uma APP degrada em Santa Catarina. Floresta e Ambiente, v. 22, n. 2, 2015, p. 194-203.

SANTOS, C. L.; SILVA, O. G.; VITAL, S. R. O.; WANDERLEY, L. S. A. Análise de suscetibilidade à ocorrência de enchentes e inundações na bacia do rio Jaguaribe - João Pessoa/PB. Revista Brasileira de Geografia Física, v. 11, n. 5, 2018, p. 1876-1888

SILVA, L. P. (2016). Hidrologia: engenharia e meio ambiente. 1 ed. Rio de Janeiro: Elsevier. 330 p.

SOARES, L. S.; LOPES, W. G. R.; CASTRO, A. C. L.; SILVA, E. V.; ARAUJO, G. C.; MOREIRA, M. S.; FRANÇA, V. L.; MENDES, K. C. Analysis of spatiotemporal changes in land use and land cover in sub-watersheds of the Lower Itapecuru River in the State of Maranhão, Brazil. Revista do Departamento de Geografia, v. 34, 2017, p. 55-67.

SOUZA, B. L.; FRASSON, F. S.; VIEIRA, M. F.; JESUS, S. C. S.; PINHO, R. G.; SILVA, R. W. S. Estudo sobre o Córrego da Onça em Três Lagoas - MS e sua atual situação. Conexão Eletrônica, v. 15, n.1, 2018, p. 570-581.

TAM, V. T.; NGA, T. T. V. Assessment of urbanization impact on groundwater resources in Hanoi, Vietnam. Journal of Environmental Management, v. 227, 2018, p. 107-116.

TUCCI, C. E. M. (2004). Hidrologia: Ciência e Aplicação. Editora UFRGS. Porto Alegre - RS. 943 p.

UNITED NATIONS. World Urbanization Prospects: The 2014 Revision. Department of Economic and Social Affairs. Population Division (Org.). Nova York: 2015. 517 p.

VILLELA, S. M.; MATTOS, A. (1975). Hidrologia Aplicada. McGraw-Hill, São Paulo - SP. 245p.

WALSH, C. J.; ROY, A. H.; FEMINELLA, J. W.; COTTINGHAM, P. D.; GROFFMAN, P. M.; MORGAN II, R. O. The urban stream syndrome: current knowledge and the search. Journal of the North American Benthological Society, v. 24, n. 3, 2005, p. 706-723.

WANG, J.; FU, Z.; QIAO, H.; LIU, F. Assessment of eutrophication and water quality in the estuarine area of Lake Wuli, Lake Taihu, China. Science of The Total Environment, v. 650, n. 1, 2019, p. 1392-1402.

ZAMBRANO, K. T.; POLETO, C.; OLIVEIRA, J. N. A comparative analysis on water quality in an urban watershed. Management of Environmental Quality: An International Journal, v. 28, 2017, p. 566-578. 